\title{
Body fatness as a cause of cancer: epidemiologic clues to biologic mechanisms
}

Correspondence should be addressed to T Byers

Email

Tim.Byers@ucdenver.edu

\begin{abstract}
Carrying excess body fat is a leading cause of cancer. Epidemiologic evidence gives strong clues about the mechanisms that link excess adiposity to risk for several cancer sites. For postmenopausal breast cancer and endometrial cancer, the hyper-estrogenic state that is induced by excess body fatness is the likely cause. For esophageal cancer and gallbladder cancer, chronic local inflammation induced by acid reflux and gallstones is the likely cause, and for liver cancer, local inflammation induced by hepatic fatty infiltration is the likely cause. However, for several other cancers known to be associated with excess adiposity, including cancers of the colon, pancreas, ovary, kidney, and prostate, specific causes are not known. Possible candidates include elevated systemic or local tissue inflammation induced by adiposity and effects of the elevated levels of leptin, insulin, IGFs, and depressed immune function that are seen with excess adiposity. There is growing evidence that intentional weight loss not only reduces circulating levels of cancer-associated factors but that it also reduces cancer incidence and recurrence. Better research is needed to understand the mechanisms that link excess body fat to cancer risk as well as to understand the amount of weight loss needed for substantial cancer risk reduction. Finally, as we develop better understanding of the mediators of the effects of excess body fatness on cancer risk, we should identify pharmacologic interventions that target those mediators so that they can be used to complement weight loss in order to reduce cancer risk.
\end{abstract}

Key Words

- obesity

- neoplasia

\section{Introduction}

In 2007, the World Cancer Research Fund (WCRF) conducted a thorough systematic review of the evidence that links various nutritional factors to cancer risk and concluded that carrying excess body fat is a cause of cancer at several sites (World Cancer Research Fund 2007). About 20\% of these obesity-associated cancers in the United States can be attributed to excess adiposity per se. Although the proportion of cancers caused by excess adiposity is lower in many other countries because of their lower levels of adiposity, the impact of obesity on cancer risk among those who are obese is similar around the world. The WCRF has estimated that excess body fatness causes about 17\% of obesityassociated cancers in Great Britain, 13\% in Brazil, and $11 \%$ in China (World Cancer Research Fund 2009). Arnold et al. (2015) recently estimated that 3.6\% of all incident cancers in the world in 2013 were caused by obesity.

Published by Bioscientifica Ltd. 
In the present review, we focus attention largely on evidence that ties excess adiposity to cancer risk in the United States, but as documented by the WCRF, obesity is a major risk factor for cancer everywhere (World Cancer Research Fund 2007). We consider the evidence for the cancer-causing effects of excess adiposity across a wide range of BMIs, including the categories known as 'overweight' (BMI levels $25-29 \mathrm{~kg} / \mathrm{m}^{2}$ ) and 'obesity' (BMI levels $30 \mathrm{~kg} / \mathrm{m}^{2}$ and greater). In the present review, we use the terms 'excess adiposity' and 'excess body fatness' interchangeably to refer to the combined effects of overweight and obesity. We use as risk estimates those that are reasonably attributed to the independent effects of overweight and obesity, separated by multivariate adjustment where possible from other potential confounding factors, including socio-demographic factors and other nutritional factors, such as diet quality and physical activity. Physical activity is an especially important potential confounder of the association between cancer and excess adiposity, because it is strongly inversely correlated with adiposity and is itself an independent risk factor for several cancer sites.

Despite the importance of excess adiposity as a cause of cancer, our understanding of the mechanisms that link levels of body fatness to cancer occurrence is very incomplete (De Pergola \& Silvestris 2013, Dobbins et al. 2013). For some cancer sites, such as the breast, endometrium, and esophagus, the epidemiologic evidence points to specific mechanisms, but for most other sites, the mechanisms are not known. In the present review, we describe the epidemiologic evidence that ties levels of body fatness to cancer at specific sites and discuss what we know and what we do not know based on epidemiologic clues that point to the mediating mechanisms that link excess adiposity to increased cancer risk.

Because excess adiposity is such a major cancer risk factor, it is surprising that the discovery of this relationship seems to have been so recent. In the 1980s, Larry Garfinkel, a statistician working for the American Cancer Society (ACS), noticed that the actuarial evidence from life insurance companies that tied relative weight (weight as a function of height) to increased overall mortality could also be seen for cancer-specific mortality in a large cohort of Americans assembled by the ACS (Garfinkel 1985). He reported that relative weight was positively associated with cancer incidence for many different cancer sites. At that time, obesity was not widely accepted as a cancer risk factor, in part because of the nonspecificity of the obesitycancer connection (which was observed for many different cancer sites) and also because of the possibility that obesity might be only a marker of some aspects of the diet that were the more direct causes. When Calle et al. (2003) made similar observations about the cancer mortality connection to excess adiposity in a second ACS cohort 20 years later, the world took greater notice, in part because a year earlier the International Agency for Research on Cancer (IARC) had published a carcinogenesis handbook on obesity, which concluded that obesity was among the most important risk factors for cancer worldwide (International Agency for Research on Cancer 2002). Over the past 20 years, there has been a persistently accumulating body of evidence linking excess adiposity to cancer risk around the world.

We first examine the relationship between excess adiposity and circulating biomarkers of cancer risk; then we summarize the epidemiologic evidence, site by site, for the nine cancer sites for which the WCRF has concluded that evidence is convincing of a relationship between obesity and cancer risk (the breast in postmenopausal women, ovary, endometrium, colon, esophagus, gallbladder, pancreas, kidney, and prostate) and also for liver cancer, for which recent evidence strongly suggests a causal connection. The present summaries emphasize the specific aspects of epidemiologic evidence that are clues to the biological mechanisms that explain those relationships. We then close with comments about the priorities for both public health and research on questions regarding excess body fat and cancer.

\section{Cancer-relevant biomarkers and obesity}

Excess body fatness is associated with increased circulating concentrations of many types of compounds that are known to increase cancer risk via pathways that involve hormonal control, cellular proliferation, and immunity (Byers \& Sedjo 2011, De Pergola \& Silvestris 2013). After menopause, aromatase activity within adipose tissues constitutes the predominant source of endogenous estrogens. Among postmenopausal women, there is a clear positive association between BMI and circulating estrogens and also an inverse association between BMI and levels of sex hormone binding globulin (Hankinson et al. 1995). Intentional weight loss leads to substantial decreases in levels of circulating estrogens, with an $\sim 3 \%$ decline in estrogen levels for every $1 \%$ of loss of body weight (Byers \& Sedjo 2011). It is important to note, however, that those reductions in estrogens with weight loss have only been documented in the relative short term (6-12 months). The relationship between circulating estrogens and patterns of persistent weight

Published by Bioscientifica Ltd. 
loss, weight regain, and weight cycling is unknown over the longer term.

Excess adiposity is a condition of hyper-inflammatory stress. This hyper-inflammatory state is thought to explain at least part of the association between excess adiposity and various other chronic conditions, including cardiovascular disease, diabetes, and arthritis, and it may also be relevant for cancer. There is a strong positive association between BMI and levels of cytokines in the circulation (Kitahara et al. 2014). Intentional weight loss leads to substantial decreases in levels of circulating cytokines, with an $\sim 2 \%$ decline in circulating levels for every $1 \%$ of loss of body weight (Byers \& Sedjo 2011). The immediate effects of acute weight loss following bariatric surgery on reducing levels of circulating cytokines are especially dramatic (Bueter et al. 2010). However, as with estrogens, the reductions in cytokine levels with weight loss have only been documented in the relative short term, but the longer-term relationships between circulating cytokines and weight patterns are still unknown.

There are many other potential cancer-relevant compounds in the circulation that have been considered cancer biomarkers and that are also associated with excess adiposity, including insulin, insulin-like growth factor 1 (IGF1), IGF-binding protein 3 (IGFBP3), and leptin (Byers $\&$ Sedjo 2011). Although weight loss reduces insulin (Look AHEAD Research Group 2007), the effect of weight loss on circulating concentrations of IGF and IGFBPs is less clear (Byers \& Sedjo 2011, Mason et al. 2013). Insulin as well as IGF and IGFBPs are growth factors that have mitogenic and anti-apoptotic properties (Louie et al. 2013). IGF and IGFBPs have been found to be associated with colorectal cancer and (less consistently) also with breast cancer (Endogenous Hormones and Breast Cancer Collaborative Group 2010, Rinaldi et al. 2010). Leptin is associated with a risk for cancer, but its independent effects are uncertain in part because it is so highly correlated with levels of adiposity. Also tied to the hyper-inflammatory state of obesity is a mild chronic suppression of immune function (Louie et al. 2013), so immune surveillance may be an important early event that contributes to the obesity-cancer connection.

\section{Breast cancer}

The WCRF has estimated that $17 \%$ of incident postmenopausal breast cancer cases in the United States can be attributed to excess adiposity (World Cancer Research Fund 2009, 2010). The relationship between excess adiposity and breast cancer risk is quite different in different age groups, however. Among premenopausal women, obesity is associated with a reduced risk for breast cancer, but among postmenopausal women, obesity is associated with an increased risk (Carmichael \& Bates 2004). This difference by age is likely a result of the changes with age in the source of the hormonal drivers of cellular activity in the breast. In premenopause, when female hormones come from the ovaries, any factor that affects ovarian function will alter circulating hormone levels. Excess adiposity is one of those factors. Women with fewer menstrual cycles per year, longer cycles, and/or irregular cycles are at a lower risk of breast cancer, presumably because of some degree of ovarian insufficiency (Garland et al. 1998). Women who are obese tend to have irregular menses as well as reduced fertility; hence, ovarian dysfunction may explain the apparent 'protective' relationship between excess adiposity and breast cancer risk that has been observed among premenopausal women. Among premenopausal women, circulating estrogens are not consistently found to be associated with breast cancer, although a positive relationship has been observed with circulating testosterone (Kaaks et al. 2014a).

After menopause, when adipose tissue becomes the primary source of circulating estrogens, the association between excess adiposity and breast cancer risk becomes strongly positive, with progressively increasing risk with increasing BMI (Key et al. 2003, Ritte et al. 2012). Serum estrogen levels have been shown to be positively associated with breast cancer risk in prospective cohort studies, and postmenopausal hormone replacement therapy increases breast cancer risk, so estrogens and progestins clearly play roles in breast cancer etiology (Key et al. 2003, Anderson et al. 2004, Endogenous Hormones and Breast Cancer Collaborative Group 2011, 2013, Ritte et al. 2012). The observation that obesity does not appear to be a risk factor among women who are using hormone replacement therapy suggests that elevated estrogen levels, regardless of whether they come from endogenous or exogenous sources, increase breast cancer risk, and those effects are not additive. Because BMI is known to be positively associated with circulating estrogen levels, it is reasonable to conclude that the obesity-breast cancer association observed among postmenopausal women is mediated by estrogens. Further support of that hypothesis comes from comparing the BMI-breast cancer association among the two major subtypes of breast cancer - those that express estrogen receptors (ER-positive) and those that do not (ER-negative). Excess adiposity has been associated with increased breast cancer risk for ER-positive breast cancers but not for ER-negative breast cancers

Published by Bioscientifica Ltd. 
in most studies, although in a large cohort, the risk for postmenopausal ER-negative breast cancer was also marginally increased by obesity among women who had never used hormone replacement therapy (Ritte et al. 2012). Overall, the epidemiologic evidence is compelling that among postmenopausal women, the BMI-breast cancer relationship is driven mostly by the production of endogenous estrogens by aromatase activity in adipose tissues.

It is important to note that even though excess adiposity is positively associated with only postmenopausal breast cancer risk, it is positively associated with breast cancer recurrence and breast cancer-specific mortality among both premenopausal and postmenopausal women with breast cancer (Protani et al. 2010). Women who have excess adiposity at diagnosis, regardless of their age and regardless of their ER subtype, experience a higher risk of breast cancer recurrence and breast cancer-specific mortality than do women who do not carry excess body fat at the time of diagnosis. This adverse effect of adiposity on breast cancer prognosis is also seen among women who have been treated with anti-estrogens (Protani et al. 2010). These observations suggest different mechanisms for how excess body fat affects cancer incidence as compared to cancer recurrence. Hence, although estrogens are quite likely the mechanism through which the risk for postmenopausal breast cancer incidence is increased by excess adiposity, other factors, such as circulating or local tissue cytokines, IGF, and/or immune function, might be the mechanisms through which cancer recurrence risk is increased for women with excess adiposity at the time of diagnosis (Endogenous Hormones and Breast Cancer Collaborative Group 2010, Kaaks et al. 2014b).

Evidence suggests that a reduction of breast cancer risk is possible with weight loss. Because intentional weight loss in which lost weight is maintained over multiple years is relatively infrequent, only a few studies have evaluated this relationship. Prospective studies report a decrease in the incidence of postmenopausal breast cancer among women who lost weight and kept it off for several years (Parker \& Folsom 2003, Harvie et al. 2005, Eliassen et al. 2006, Byers \& Sedjo 2011). The Women's Intervention Nutrition Study was a randomized controlled trial of a lowfat dietary intervention among breast cancer survivors (Chlebowski et al. 2006). Although that trial was not specifically designed to evaluate weight loss changes, the caloric balance modifications associated with the low-fat dietary intervention led to a difference in body weight of about $6 \mathrm{lbs}$ between the treatment groups after 5 years, which was accompanied by a $24 \%$ risk reduction of breast cancer recurrence among women with ER-negative cancers. Studies that investigated patients who have undergone bariatric surgery have demonstrated a substantial reduction in cancer risk associated with the rapid and substantial weight loss following surgery (Christou et al. 2008, Sjöström et al. 2009, Tee et al. 2013). Interestingly, the effect of bariatric surgery on reducing cancer risk appears to occur primarily among women rather than men, which suggests that there may be a predominant early effect mediated by reductions in circulating sex steroid hormone levels.

\section{Endometrial cancer}

The WCRF has estimated that 50\% of incident endometrial cancer cases in the United States can be attributed to excess adiposity (World Cancer Research Fund 2009, 2013). The impact of excess body fat on endometrial cancer risk is much greater than it is on breast cancer, likely because circulating estrogens play a much larger role in endometrial cancer development. Postmenopausal estrogen hormonal replacement therapies are known to increase endometrial cancer risk (Allen et al. 2010), and levels of estrogens in the circulation are strongly associated with an increased risk for endometrial cancer (Allen et al. 2008). Bariatric surgery decreases the risk for endometrial cancer (Ward et al. 2014), and a pattern of weight cycling (repeated cycles of weight loss followed by regain) has been found to be associated with increased endometrial cancer risk (Stevens et al. 2012, Nagle et al. 2013). Endometrial cancers are commonly categorized into two types. Type 1 endometrial cancers, which comprise about $80 \%$ of all cases, are mostly endometrioid adenocarcinomas and tend to be hormone sensitive, whereas type 2 endometrial cancers, which represent about $20 \%$ of all cases, tend to be less hormone sensitive and to have poorer prognoses (Setiawan et al. 2013). Obesity is associated with both types of endometrial cancer, but the strength of the association is greater for type 1 (estrogen-driven) cancers (Setiawan et al. 2013). The positive association between BMI and circulating estrogens among postmenopausal women is likely the main mediator of the obesityendometrial cancer relationship, although other factors, such as circulating or local tissue cytokines and insulin, may also play a role (Cust et al. 2007, Dossus et al. 2010).

\section{Ovarian cancer}

The WCRF has estimated that 5\% of incident ovarian cancer cases in the United States can be attributed to excess adiposity (World Cancer Research Fund 2009,

Published by Bioscientifica Ltd 
2014a, Lahmann et al. 2010). BMI has been observed to be more strongly associated with less common (and less lethal) histologic subtypes of ovarian cancer (Olsen et al. 2013). Apart from the use of oral contraceptives to reduce risk, little is understood about the etiology of ovarian cancer. The mechanisms that link excess adiposity to ovarian cancer are only speculative, but they include systemic and local tissue inflammation. In a prospective analysis from the Prostate, Lung, Colorectal and Ovarian Cancer Screening Trial cohort, substantial positive associations were observed between ovarian cancer risk and elevated concentrations of CRP, IL $1 \alpha$, and TNF- $\alpha$ (Trabert et al. 2014). Supporting the hypothesis that the hyperinflammatory state of obesity is an important mechanism for ovarian cancer is the observation from a recent metaanalysis of 14 case-control and seven cohort studies that ovarian cancer risk is reduced with frequent aspirin use (Baandrup et al. 2013).

\section{Colorectal cancer}

The WCRF has estimated that 15\% of incident colorectal cancer cases in the United States can be attributed to excess adiposity (World Cancer Research Fund 2009, 2011). BMI is more consistently associated with colon cancer than it is with rectal cancer (Robsahm et al. 2013), and adult weight gain increases the risk of colon cancer but not rectal cancer among both men and women (Aleksandrova et al. 2013a). The mechanism that explains this association is not known, but sex differences in the relationship between excess adiposity and colon cancer suggest that mechanisms apart from hormonal ones are involved. The association between obesity and colon cancer risk is weaker among women than it is among men (Aleksandrova et al. 2013b), which may well be a result of the protective role that estrogens play for colon cancer in women (Rossouw et al. 2002). Even though the colon cancer association with excess adiposity is weaker among women than it is among men, it is important to note that there still remains an increased risk for colorectal cancer with excess adiposity among women. This suggests that a mechanism such as cytokines and/or IGF might mediate the link between excess adiposity and colon cancer risk in both sexes (Aleksandrova et al. 2010, Ho et al. 2012). Weight loss appears to produce a moderate reduction on colorectal cancer risk. A meta-analysis of four studies reported a $27 \%$ reduction in colorectal cancer risk among obese individuals who underwent bariatric surgery (Afshar et al. 2014).

\section{Esophageal cancer}

The WCRF has estimated that $35 \%$ of cases of incident adenocarcinoma of the esophagus in the United States can be attributed to excess adiposity (World Cancer Research Fund 2009). There have been two opposite trends in esophageal cancer incidence in the United States over the past 20 years - a persistent decline in the risk of squamous cell cancer of the esophagus and a persistent increase in the risk of adenocarcinoma of the esophagus. Squamous cell carcinoma of the esophagus occurs mostly in the upper two-thirds of the esophagus, and it is increased by factors such as tobacco and alcohol. The declining use of tobacco in the United States is likely the main factor that has led to the declining incidence of squamous cell cancer of the upper esophagus. In contrast, esophageal adenocarcinoma occurs typically in the lower one-third of the esophagus, and it is clearly on the rise. Adenocarcinoma of the esophagus typically arises from a mucosa that has been chronically damaged, most commonly by the chronic reflux of acidic contents from the stomach into the lower esophagus. Obesity is the most important risk factor for acid reflux, which likely explains much of its relationship with adenocarcinoma of the esophagus (Singh et al. 2013). Although stomach cancer is not associated with obesity overall, cancers of the upper part of the stomach (gastric cardia) near the esophageal juncture are associated with excess adiposity (Chen et al. 2013).

\section{Gallbladder cancer}

The WCRF has estimated that $21 \%$ of incident gallbladder cancer cases in the United States can be attributed to excess adiposity (World Cancer Research Fund 2009, Wang et al. 2012a). Gallstones are a major risk factor for gallbladder cancer, and obesity is a major risk factor for gallstones. Much of the association between excess body fatness and gallbladder cancer is likely explained by the precipitation of bile acids into stones in the gallbladder, which causes chronic local tissue inflammation.

\section{Liver cancer}

The WCRF has found conclusive evidence that links liver cancer to excess adiposity, and substantial evidence has been accumulated in recent years to support that conclusion (Wang et al. 2012b, Chen et al. 2012, Chen et al. 2013, Schlesinger et al. 2013, World Cancer Research Fund International 2015). Clearly, chronic viral infection in the liver is the leading cause of liver cancer, but any other factors that also cause hepatocellular injury

Published by Bioscientifica Ltd 
and hepatocellular proliferation, including alcohol use, chronic exposure to other chemicals, and excess adiposity, can increase risk. The mechanism that ties excess adiposity to liver cancer likely includes fatty infiltration and its accompanying chronic local inflammation (Aleksandrova et al. 2014). The high levels of circulating leptin associated with excess adiposity may also play a role (Polyzos et al. 2011). The continuing epidemic of chronic hepatitis $\mathrm{C}$ virus infection, combined with the obesity epidemic, have led to persistent increases in the incidence of hepatocellular cancer in the United Stated over the past 30 years. Although excess body fatness is associated with an increased risk for incident liver cancer, whether that excess risk might be reduced with weight loss is unknown.

\section{Pancreatic cancer}

The WCRF has estimated that 19\% of incident pancreatic cancer cases in the United States can be attributed to excess adiposity (World Cancer Research Fund 2009, 2012, Arslan et al. 2010, Genkinger et al. 2011). Apart from adiposity and the rare hereditary forms of pancreatic cancer, there are few known pancreatic cancer risk factors. The mechanism that ties excess adiposity to pancreatic cancer risk are unknown, but they may well be similar to those for the liver and may involve fatty infiltration of the pancreas with resulting local tissue inflammation, perhaps also including effects of circulating cytokines, IGF, and/or insulin.

\section{Kidney cancer}

The WCRF has estimated that 24\% of incident kidney cancer cases in the United States can be attributed to excess adiposity (World Cancer Research Fund 2009, Ljungberg et al. 2011). Apart from obesity, there are few known risk factors for kidney cancer (Wang \& Xu 2014). Clearly, mechanical factors like those that may explain esophageal cancer risk, or fatty infiltrates, like those that may explain liver cancer risk, are not relevant for kidney cancers, where circulating factors that are tied to chronic inflammation, growth stimulating factors, and/or immune dysfunction are more likely.

\section{Prostate cancer}

The WCRF has estimated that $11 \%$ of incident advanced prostate cancer cases in the United States can be attributed to excess adiposity (World Cancer Research Fund 2009, 2014b, Golabek et al. 2014, Hu et al. 2014). There are few known risk factors for prostate cancer. IGFs have been found to be modestly associated with prostate cancer risk (Price et al. 2012). One of the problems with prostate cancer epidemiology is that prostate cancer is a highly prevalent disease, so sorting out the prostate cancers that are more malignant from those that have more benign behavior is necessary in order to avoid dilution of the effects of any risk factor on this clinically important disease. Obesity is modestly associated with only the clinically aggressive forms of prostate cancer (Gleason scores of 7 or greater). One of the interesting complexities in prostate cancer epidemiology is the relationship between prostate cancer risk and the risk factors of excess adiposity and type 2 diabetes. Prostate cancer risk is lower among men with type 2 diabetes, despite the fact that obesity is a major driver for type 2 diabetes (Tsilidis et al. 2015). This may in part be a result of lower levels of androstenedione, total testosterone, and IGFBP3 among men with type 2 diabetes.

\section{Discussion}

Several common cancers are caused in part by carrying excess body fat. Because excess adiposity is such a common condition, there is a substantial preventable fraction (also known as the 'population attributable risk', or the proportion of all cases that could be prevented). The WCRF has estimated preventable fractions from obesity in the United States, as summarized in Table 1. Also in Table 1, we list what we believe are the strongest hypotheses for the mechanisms that tie obesity to cancer risk. The relationships between diet, physical activity, excess adiposity, and their pathways to cancer via mechanisms are summarized in Fig. 1. Although diet, physical activity, and excess adiposity are all inherently correlated, it is important to realize that the mechanistic pathways that connect them to cancer may not always be the same, and they may vary across different cancer sites.

Of course, there should be many question marks within both Table 1 and Fig. 1, because general explanations such as 'inflammation' are hardly specific enough to be regarded as true mechanistic explanations. The relationships between the levels of inflammatory cytokines in the circulation and the levels present locally in tissues are often weak, and local tissue inflammation may be more relevant for driving cellular proliferation than systemic inflammatory levels are. In addition, many factors that were thought to be capable of driving cancer cell growth, such as IGF, leptin, and insulin, have often not been observed to be any more strongly associated with

Published by Bioscientifica Ltd 
Table 1 Summary of the preventable fraction (population attributable risk) for selected cancers resulting from excess adiposity in the United States, as estimated by the World Cancer Research Foundation (World Cancer Research Fund 2009) and the possible mechanisms that link excess adiposity to cancer risk for selected cancers

\begin{tabular}{|c|c|c|}
\hline Cancer site & $\begin{array}{l}\text { Relative risk per } \\
\text { five BMI units }\end{array}$ & $\begin{array}{l}\text { Preventable } \\
\text { fraction (\%) }\end{array}$ \\
\hline Breast (postmenopausal) & 1.12 & 17 \\
\hline Endometrial & 1.50 & 50 \\
\hline Ovary & 1.06 & 5 \\
\hline Colorectal & 1.10 & 16 \\
\hline Esophageal & $1.95^{b}$ & 35 \\
\hline Gallbladder & 1.23 & 21 \\
\hline Pancreatic & 1.10 & 19 \\
\hline Kidney & 1.31 & 24 \\
\hline Prostate (advanced) & 1.08 & 11 \\
\hline
\end{tabular}

\section{Most likely mechanisms}

Endogenous circulating estrogens from adipose tissue Endogenous circulating estrogens from adipose tissue Systemic or local tissue inflammation Systemic inflammation and other circulating factors ${ }^{\mathrm{a}}$ Acid reflux causing local inflammation Gallstones causing local inflammation Systemic inflammation and other circulating factors ${ }^{a}$ Systemic inflammation and other circulating factors ${ }^{a}$ Systemic inflammation and other circulating factors ${ }^{a}$

${ }^{a}$ Factors include leptin, IGFs, IGFBPs, and insulin.

${ }^{b}$ Mean of both sexes for high vs low categories of BMI (World Cancer Research Fund 2009).

cancer risk than BMI is per se. Hence, whether many of these factors that are correlated with adiposity are really primary factors or whether they are only bystanders to other factors that affect cancer risk is uncertain. There is particular uncertainty about the mechanisms that link excess adiposity to risk for cancers of the colon, prostate, pancreas, ovary, and kidney. In contrast, we see the evidence to be compelling for the mechanisms that explain most of the risk from excess adiposity for cancers of the endometrium, liver, gallbladder, esophagus, and the breast among postmenopausal women.

Clearly the best way to prevent the fraction of cancers that are attributable to excess adiposity is to prevent excessive weight gain throughout life. However, the more pressing question for the large proportion of adults who are already carrying excess body fat is whether anything can be done to reduce their excess cancer risk. The studies of the effects of bariatric surgery on cancer risk are very encouraging, in that there may be substantial cancer risk reductions after only a few years following intentional weight loss. Those findings are quite consistent with observational studies that indicate a lower cancer risk among people who have intentionally lost weight in adulthood (Byers \& Sedjo 2011). Weight loss is known to reduce the levels of cancer-associated circulating factors, including estrogens, cytokines, insulin, and leptin. However, we know little about whether the short-term reductions in those factors with intentional weight loss that are well documented over months will be maintained with weight loss over years, because studies to date have followed subjects for only short periods of time. Longerterm follow-up studies are needed to assess the effects of intentional weight loss over years on cancer-relevant biomarkers and hence on the apparent cancer risk reduction. In addition to using weight loss trials to study the effects of weight loss on biomarkers of cancer risk, we also need weight loss trials that are sufficiently powered to directly assess the effects on cancer risk and/or recurrence. Finally, recognizing that sufficient intentional weight loss may not be achievable by many, a better understanding of the mechanisms that link excess adiposity to cancer risk could lead to pharmacologic interventions to break those links.

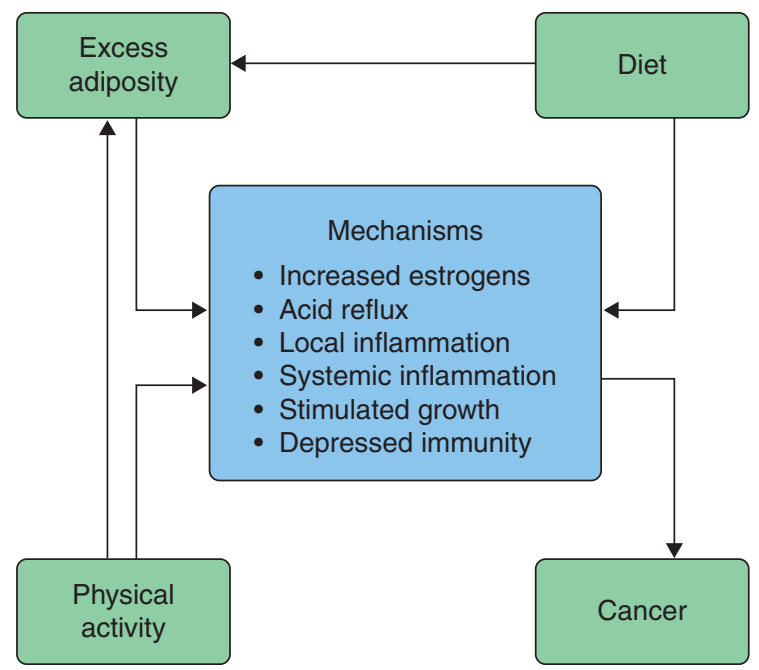

Figure 1

The inter-relationships between excess adiposity, diet, physical activity, mediating mechanisms, and cancer risk.

Published by Bioscientifica Ltd. 


\section{Declaration of interest}

The authors declare that there is no conflict of interest that could be perceived as prejudicing the impartiality of the review.

\section{Funding}

This review did not receive any specific grant from any funding agency in the public, commercial or not-for-profit sector.

\section{References}

Afshar S, Kelly SB, Seymour K, Lara J, Woodcock S \& Mathers JC 2014 The effects of bariatric surgery on colorectal cancer risk: systematic review and meta-analysis. Obesity Surgery 24 1793-1799. (doi:10.1007/s11695014-1359-y)

Aleksandrova K, Jenab M, Boeing H, Jansen E, Bueno-de-Mesquita HB, Rinaldi S, Riboli E, Overvad K, Dahm CC, Olsen A et al. 2010 Circulating C-reactive protein concentrations and risks of colon and rectal cancer: a nested case-control study within the European Prospective Investigation into Cancer and Nutrition. American Journal of Epidemiology 172 407-418. (doi:10.1093/aje/kwq135)

Aleksandrova K, Nimptsch K \& Pischon T 2013a Obesity and colorectal cancer. Frontiers in Bioscience 5 61-77.

Aleksandrova K, Pischon T, Buijsse B, May AM, Peeters PH, Bueno-de-Mesquita HB, Jenab M, Fedirko V, Dahm CC, Siersema PD et al. 2013b Adult weight change and risk of colorectal cancer in the European Prospective Investigation into Cancer and Nutrition. European Journal of Cancer 49 3526-3536. (doi:10.1016/j.ejca.2013. 06.021)

Aleksandrova K, Boeing H, Nöthlings U, Jenab M, Fedirko V, Kaaks R, Lukanova A, Trichopoulou A, Trichopoulos D, Boffetta P et al. 2014 Inflammatory and metabolic biomarkers and risk of liver and biliary tract cancer. Hepatology 60 858-871. (doi:10.1002/hep.27016)

Allen NE, Key TJ, Dossus L, Rinaldi S, Cust A, Lukanova A, Peeters PH, Onland-Moret NC, Lahmann PH, Berrino F et al. 2008 Endogenous sex hormones and endometrial cancer risk in women in the European Prospective Investigation into Cancer and Nutrition (EPIC). EndocrineRelated Cancer 15 485-497. (doi:10.1677/ERC-07-0064)

Allen NE, Tsilidis KK, Key TJ, Dossus L, Kaaks R, Lund E, Bakken K, Gavrilyuk O, Overvad K, Tjønneland A et al. 2010 Menopausal hormone therapy and risk of endometrial carcinoma among postmenopausal women in the European Prospective Investigation into Cancer and Nutrition. American Journal of Epidemiology 172 1394-1403. (doi:10.1093/aje/kwq300)

Anderson GL, Limacher M, Assaf AR, Bassford T, Beresford SA, Black H, Bonds D, Brunner R, Brzyski R, Caan B et al. 2004 Effects of conjugated equine estrogen in postmenopausal women with hysterectomy: the Women's Health Initiative randomized controlled trial. Journal of the American Medical Association 291 1701-1712. (doi:10.1001/jama.291. 14.1701)

Arnold M, Pandeya N, Byrnes G, Renehan AG, Stevens GA, Ezzati M, Ferlay J, Miranda JJ, Romieu I, Dikshit R et al. 2015 Global burden of cancer attributable to high body mass index in 2012: a population-based study. Lancet. Oncology 16 36-46. (doi:10.1016/S1470-2045(14)71123-4)

Arslan AA, Helzlsouer KJ, Kooperberg C, Shu XO, Steplowski E, Buenode-Mesquita HB, Fuchs CS, Gross MD, Jacobs EJ, Lacroix AZ et al. 2010 Anthropometric measures, body mass index, and pancreatic cancer: a pooled analysis from the Pancreatic Cancer Cohort Consortium (PanScan). Archives of Internal Medicine 170 791-802. (doi:10.1001/ archinternmed.2010.63)

Baandrup L, Faber MT, Christensen J, Jensen A, Andersen KK, Friis S \& Kjaer SK 2013 Nonsteroidal anti-inflammatory drugs and risk of ovarian cancer: systematic review and meta-analysis of observational studies. Acta Obstetricia et Gynecologica Scandinavica 92 245-255. (doi:10.1111/ aogs.12069)

Bueter M, Dubb SS, Gill A, Joannou L, Ahmed A, Frankel AH, Tam FW \& le Roux CW 2010 Renal cytokines improve early after bariatric surgery. British Journal of Surgery 97 1838-1844. (doi:10.1002/bjs.7264)

Byers T \& Sedjo RL 2011 Does intentional weight loss reduce cancer risk? Diabetes, Obesity \& Metabolism 13 1063-1072. (doi:10.1111/j.14631326.2011.01464.x)

Calle EE, Rodriguez C, Walker-Thurmond K \& Thun MJ 2003 Overweight, obesity, and mortality from cancer in a prospectively studied cohort of U.S. adults. New England Journal of Medicine 348 1625-1638. (doi:10.1056/NEJMoa021423)

Carmichael AR \& Bates T 2004 Obesity and breast cancer: a review of the literature. Breast 13 85-92. (doi:10.1016/j.breast.2003.03.001)

Chen Y, Wang X, Wang J, Yan Z \& Luo J 2012 Excess body weight and the risk of primary liver cancer: an updated meta-analysis of prospective studies. European Journal of Cancer 48 2137-2145. (doi:10.1016/j.ejca. 2012.02.063)

Chen Y, Liu L, Wang X, Wang J, Yan Z, Cheng J, Gong G \& Li G 2013 Body mass index and risk of gastric cancer: a meta-analysis of a population with more than ten million from 24 prospective studies. Cancer Epidemiology, Biomarkers \& Prevention 22 1395-1408. (doi:10.1158/ 1055-9965.EPI-13-0042)

Chlebowski RT, Blackburn GL, Thomson CA, Nixon DW, Shapiro A, Hoy MK, Goodman MT, Giuliano AE, Karanja N, McAndrew P et al. 2006 Dietary fat reduction and breast cancer outcome: interim efficacy results from the Women's Intervention Nutrition Study. Journal of the National Cancer Institute 98 1767-1776. (doi:10.1093/jnci/djj494)

Christou NV, Lieberman M, Sampalis F \& Sampalis JS 2008 Bariatric surgery reduces cancer risk in morbidly obese patients. Surgery for Obesity and Related Diseases 4 691-695. (doi:10.1016/j.soard.2008.08.025)

Cust AE, Allen NE, Rinaldi S, Dossus L, Friedenreich C, Olsen A, Tjønneland A, Overvad K, Clavel-Chapelon F, Boutron-Ruault MC et al. 2007 Serum levels of C-peptide, IGFBP-1 and IGFBP-2 and endometrial cancer risk; results from the European prospective investigation into cancer and nutrition. International Journal of Cancer 120 2656-2664. (doi:10.1002/ ijc.22578)

De Pergola G \& Silvestris F 2013 Obesity as a major risk factor for cancer. Journal of Obesity 2013 1-11. (doi:10.1155/2013/291546)

Dobbins M, Decorby K \& Choi BC 2013 The association between obesity and cancer risk: a meta-analysis of observational studies from 1985 to 2011. ISRN Preventive Medicine 2013 680536. (doi:10.5402/2013/ 680536)

Dossus L, Rinaldi S, Becker S, Lukanova A, Tjonneland A, Olsen A, Stegger J, Overvad K, Chabbert-Buffet N, Jimenez-Corona A et al. 2010 Obesity, inflammatory markers, and endometrial cancer risk: a prospective case-control study. Endocrine-Related Cancer 17 1007-1019. (doi:10.1677/ERC-10-0053)

Eliassen AH, Colditz GA, Rosner B, Willett WC \& Hankinson SE 2006 Adult weight change and risk of postmenopausal breast cancer. Journal of the American Medical Association 296 193-201. (doi:10.1001/ jama.296.2.193)

Endogenous Hormones and Breast Cancer Collaborative Group , Key TJ, Appleby PN, Reeves GK \& Roddam AW 2010 Insulin-like growth factor 1 (IGF1), IGF binding protein 3 (IGFBP3), and breast cancer risk: pooled individual data analysis of 17 prospective studies. Lancet. Oncology 11 530-542. (doi:10.1016/S1470-2045(10)70095-4)

Endogenous Hormones and Breast Cancer Collaborative Group , Key TJ, Appleby PN, Reeves GK, Roddam AW, Helzlsouer KJ, Alberg AJ, Rollison DE, Dorgan JF, Brinton LA et al. 2011 Circulating sex hormones and breast cancer risk factors in postmenopausal women: reanalysis of 13 studies. British Journal of Cancer 105 709-722. (doi:10.1038/bjc.2011.254)

Endogenous Hormones and Breast Cancer Collaborative Group , Key TJ, Appleby PN, Reeves GK, Travis RC, Alberg AJ, Barricarte A, Berrino F, Krogh V, Sieri S et al. 2013 Sex hormones and risk of breast cancer in 
premenopausal women: a collaborative reanalysis of individual participant data from seven prospective studies. Lancet. Oncology 14 1009-1019. (doi:10.1016/S1470-2045(13)70301-2)

Garfinkel L 1985 Overweight and cancer. Annals of Internal Medicine 103 1034-1036. (doi:10.7326/0003-4819-103-6-1034)

Garland M, Hunter DJ, Colditz GA, Manson JE, Stampfer MJ, Spiegelman D, Speizer F \& Willett WC 1998 Menstrual cycle characteristics and history of ovulatory infertility in relation to breast cancer risk in a large cohort of US women. American Journal of Epidemiology 147 636-643. (doi:10.1093/oxfordjournals.aje.a009504)

Genkinger JM, Spiegelman D, Anderson KE, Bernstein L, van den Brandt PA, Calle EE, English DR, Folsom AR, Freudenheim JL, Fuchs CS et al. 2011 A pooled analysis of 14 cohort studies of anthropometric factors and pancreatic cancer risk. International Journal of Cancer 129 1708-1717. (doi:10.1002/ijc.25794)

Golabek T, Bukowczan J, Chłosta P, Powroźnik J, Dobruch J \& Borówka A 2014 Obesity and prostate cancer incidence and mortality: a systematic review of prospective cohort studies. Urologia Internationalis 92 7-14. (doi:10.1159/000351325)

Hankinson SE, Willett WC, Manson JE, Hunter DJ, Colditz GA, Stampfer MJ, Longcope C \& Speizer FE 1995 Alcohol, height, and adiposity in relation to estrogen and prolactin levels in postmenopausal women. Journal of the National Cancer Institute 87 1297-1302. (doi:10.1093/jnci/87.17.1297)

Harvie M, Howell A, Vierkant RA, Kumar N, Cerhan JR, Kelemen LE, Folsom AR $\&$ Sellers TA 2005 Association of gain and loss of weight before and after menopause with of postmenopausal breast cancer in the Iowa Women's Health Study. Cancer Epidemiology, Biomarkers \& Prevention 14 656-661. (doi:10.1158/1055-9965.EPI-04-0001)

Ho GY, Wang T, Gunter MJ, Strickler HD, Cushman M, Kaplan RC, Wassertheil-Smoller S, Xue X, Rajpathak SN, Chlebowski RT et al. 2012 Adipokines linking obesity with colorectal cancer risk in postmenopausal women. Cancer Research 72 3029-3037. (doi:10.1158/00085472.CAN-11-2771)

Hu MB, Liu SH, Jiang HW, Bai PD \& Ding Q 2014 Obesity affects the biopsy-mediated detection of prostate cancer, particularly high-grade prostate cancer: a dose-response meta-analysis of 29,464 patients. PLOS ONE 9 e106677. (doi:10.1371/journal.pone.0106677)

International Agency for Research on Cancer 2002 Weight Control and Physical Activity. IARC Handbooks of Cancer prevention, Vol 6. Lyon, France: IARC Press.

Kaaks R, Tikk K, Sookthai D, Schock H, Johnson T, Tjønneland A, Olsen A, Overvad K, Clavel-Chapelon F, Dossus L et al. 2014a Premenopausal serum sex hormone levels in relation to breast cancer risk, overall and by hormone receptor status - results from the EPIC cohort. International Journal of Cancer 134 1947-1957. (doi:10.1002/ijc.28528)

Kaaks R, Johnson T, Tikk K, Sookthai D, Tjønneland A, Roswall N, Overvad K, Clavel-Chapelon F, Boutron-Ruault MC, Dossus L et al. 2014 b Insulinlike growth factor I and risk of breast cancer by age and hormone receptor status-A prospective study within the EPIC cohort. International Journal of Cancer 134 2683-2690. (doi:10.1002/ijc.28589)

Key TJ, Appleby PN, Reeves GK, Roddam A, Dorgan JF, Longcope C, Stanczyk FZ, Stephenson HE Jr, Falk RT, Miller R et al. 2003 Body mass index, serum sex hormones, and breast cancer risk in postmenopausal women. Journal of the National Cancer Institute 95 1218-1226. (doi:10.1093/jnci/djg022)

Kitahara CM, Trabert B, Katki HA, Chaturvedi AK, Kemp TJ, Pinto LA, Moore SC, Purdue MP, Wentzensen N, Hildesheim A et al. 2014 Body mass index, physical activity, and serum markers of inflammation, immunity, and insulin resistance. Cancer Epidemiology, Biomarkers \& Prevention 23 2840-2849. (doi:10.1158/1055-9965.EPI-14-0699-T)

Lahmann PH, Cust AE, Friedenreich CM, Schulz M, Lukanova A, Kaaks R, Lundin E, Tjønneland A, Halkjaer J, Severinsen MT et al. 2010 Anthropometric measures and epithelial ovarian cancer risk in the European Prospective Investigation into Cancer and Nutrition. International Journal of Cancer 126 2404-2415. (doi:10.1002/ijc.24952)
Ljungberg B, Campbell SC, Choi HY, Jacqmin D, Lee JE, Weikert S \& Kiemeney LA 2011 The epidemiology of renal cell carcinoma. European Urology 60 615-621. (doi:10.1016/j.eururo.2011.06.049)

Look AHEAD Research Group 2007 Reduction in weight and cardiovascular disease risk factors in individuals with type 2 diabetes: one-year results of the look AHEAD trial. Diabetes Care 30 1374-1383. (doi:10.2337/ dc07-0048)

Louie SM, Roberts LS \& Nomura DK 2013 Mechanisms linking obesity and cancer. Biochimica et Biophysica Acta 1831 1499-1508. (doi:10.1016/ j.bbalip.2013.02.008)

Mason C, Xiao L, Duggan C, Imayama I, Foster-Schubert KE, Kong A, Campbell KL, Wang CY, Alfano CM, Blackburn GL et al. 2013 Effects of dietary weight loss and exercise on insulin-like growth factor-I and insulin-like growth factor-binding protein-3 in postmenopausal women: a randomized controlled trial. Cancer Epidemiology, Biomarkers \& Prevention 22 1457-1463. (doi:10.1158/1055-9965.EPI-13-0337)

Nagle CM, Marquart L, Bain CJ, O'Brien S, Lahmann PH, Quinn M, Oehler MK, Obermair A, Spurdle AB, Webb PM et al. 2013 Impact of weight change and weight cycling on risk of different subtypes of endometrial cancer. European Journal of Cancer 49 2717-2726. (doi:10.1016/ j.ejca.2013.03.015)

Olsen CM, Nagle CM, Whiteman DC, Ness R, Pearce CL, Pike MC, Rossing MA, Terry KL, Wu AH, Australian Cancer Study (Ovarian Cancer) et al. 2013 Obesity and risk of ovarian cancer subtypes: evidence from the Ovarian Cancer Association Consortium. Endocrine-Related Cancer 20 251-262. (doi:10.1530/ERC-12-0395)

Parker ED \& Folsom AR 2003 Intentional weight loss and incidence of obesity-related cancers: the Iowa Women's Health Study. International Journal of Obesity and Related Metabolic Disorders 27 1447-1452. (doi:10.1038/sj.ijo.0802437)

Polyzos SA, Kountouras J, Zavos C \& Deretzi G 2011 The potential adverse role of leptin resistance in nonalcoholic fatty liver disease: a hypothesis based on critical review of the literature. Journal of Clinical Gastroenterology 45 50-54. (doi:10.1097/MCG.0b013e3181ec5c66)

Price AJ, Allen NE, Appleby PN, Crowe FL, Travis RC, Tipper SJ, Overvad K, Grønbæk H, Tjønneland A, Johnsen NF et al. 2012 Insulin-like growth factor-I concentration and risk of prostate cancer: results from the European Prospective Investigation into Cancer and Nutrition. Cancer Epidemiology, Biomarkers \& Prevention 21 1531-1541. (doi:10.1158/ 1055-9965.EPI-12-0481-T)

Protani M, Coory M \& Martin JH 2010 Effect of obesity on survival of women with breast cancer: systematic review and meta-analysis. Breast Cancer Research and Treatment 123 627-635. (doi:10.1007/ s10549-010-0990-0)

Rinaldi S, Cleveland R, Norat T, Biessy C, Rohrmann S, Linseisen J, Boeing H, Pischon T, Panico S, Agnoli C et al. 2010 Serum levels of IGF-I, IGFBP-3 and colorectal cancer risk: results from the EPIC cohort, plus a meta-analysis of prospective studies. International Journal of Cancer 126 1702-1715. (doi:10.1002/ijc.24927)

Ritte R, Lukanova A, Berrino F, Dossus L, Tjønneland A, Olsen A, Overvad TF, Overvad K, Clavel-Chapelon F, Fournier A et al. 2012 Adiposity, hormone replacement therapy use and breast cancer risk by age and hormone receptor status: a large prospective cohort study. Breast Cancer Research 14 R76. (doi:10.1186/bcr3186)

Robsahm TE, Aagnes B, Hjartåker A, Langseth H, Bray FI \& Larsen IK 2013 Body mass index, physical activity, and colorectal cancer by anatomical subsites: a systematic review and meta-analysis of cohort studies. European Journal of Cancer Prevention 22 492-505. (doi:10.1097/CEJ. Ob013e328360f434)

Rossouw JE, Anderson GL, Prentice RL, LaCroix AZ, Kooperberg C, Stefanick ML, Jackson RD, Beresford SA, Howard BV, Johnson KC et al. 2002 Risks and benefits of estrogen plus progestin in healthy postmenopausal women: principal results from the Women's Health Initiative randomized controlled trial. Journal of the American Medical Association 288 321-333. (doi:10.1001/jama.288.3.321) 
Schlesinger S, Aleksandrova K, Pischon T, Fedirko V, Jenab M, Trepo E, Boffetta P, Dahm CC, Overvad K, Tjønneland A et al. 2013 Abdominal obesity, weight gain during adulthood and risk of liver and biliary tract cancer in a European cohort. International Journal of Cancer 132 645-657. (doi:10.1002/ijc.27645)

Setiawan VW, Yang HP, Pike MC, McCann SE, Yu H, Xiang YB, Wolk A, Wentzensen N, Weiss NS, Webb PM et al. 2013 Type I and II endometrial cancers: have they different risk factors? Journal of Clinical Oncology 31 2607-2618. (doi:10.1200/JCO.2012.48.2596)

Singh S, Sharma AN, Murad MH, Buttar NS, El-Serag HB, Katzka DA \& Iyer PG 2013 Central adiposity is associated with increased risk of esophageal inflammation, metaplasia, and adenocarcinoma: a systematic review and meta-analysis. Clinical Gastroenterology and Hepatology 11 1399-1412e7. (doi:10.1016/j.cgh.2013.05.009)

Sjöström L, Gummesson A, Sjöström CD, Narbro K, Peltonen M, Wedel H, Bengtsson C, Bouchard C, Carlsson B, Dahlgren S et al. 2009 Effects of bariatric surgery on cancer incidence in obese patients in Sweden (Swedish Obesity Subjects Study): a prospective, controlled intervention trial. Lancet. Oncology 10 653-662. (doi:10.1016/S1470-2045(09)70159-7)

Stevens VL, Jacobs EJ, Sun J, McCullough ML, Patel AV, Gaudet MM, Teras LR \& Gapstur SM 2012 Weight cycling and risk of endometrial cancer. Cancer Epidemiology, Biomarkers \& Prevention 21 747-752. (doi:10.1158/ 1055-9965.EPI-12-0038)

Tee MC, Cao Y, Warnock GL, Hu FB \& Chavarro JE 2013 Effect of bariatric surgery on oncologic outcomes: a systematic review and meta-analysis. Surgical Endoscopy 27 4449-4456. (doi:10.1007/s00464-013-3127-9)

Trabert B, Pinto L, Hartge P, Kemp T, Black A, Sherman ME, Brinton LA, Pfeiffer RM, Shiels MS, Chaturvedi AK et al. 2014 Pre-diagnostic serum levels of inflammation markers and risk of ovarian cancer in the Prostate, Lung, Colorectal and Ovarian Cancer (PLCO) Screening Trial. Gynecologic Oncology 135 297-304. (doi:10.1016/j.ygyno.2014.08.025)

Tsilidis KK, Allen NE, Appleby PN, Rohrmann S, Nöthlings U, Arriola L, Gunter MJ, Chajes V, Rinaldi S, Romieu I et al. 2015 Diabetes mellitus and risk of prostate cancer in the European Prospective Investigation into Cancer and Nutrition. International Journal of Cancer 136 372-381. (doi:10.1002/ijc.28989)

Wang F \& Xu Y 2014 Body mass index and risk of renal cell cancer: a dose-response meta-analysis of published cohort studies. International Journal of Cancer 135 1673-1686. (doi:10.1002/ijc.28813)

Wang F, Wang B \& Qiao L 2012a Association between obesity and gallbladder cancer. Frontiers in Bioscience 17 2550-2558. (doi:10.2741/4070)
Wang Y, Wang B, Shen F, Fan J \& Cao H $2012 b$ Body mass index and risk of primary liver cancer: a meta-analysis of prospective studies. Oncologist 17 1461-1468. (doi:10.1634/theoncologist.2012-0066)

Ward KK, Roncancio AM, Shah NR, Davis MA, Saenz CC, McHale MT \& Plaxe SC 2014 Bariatric surgery decreases the risk of uterine malignancy. Gynecologic Oncology 133 63-66. (doi:10.1016/j.ygyno. 2013.11.012)

World Cancer Research Fund/American Institute for Cancer Research 2007 Food, Nutrition, Physical Activity, and the Prevention of Cancer: a Global Perspective. Washington, DC, USA: AICR.

World Cancer Research Fund/American Institute for Cancer Research 2009 Policy and Action for Cancer Prevention. Food, Nutrition, and Physical Activity: a Global Perspective. Washington DC, USA: AICR.

World Cancer Research Fund/American Institute for Cancer Research 2010 Continuous Update Project Report. Food, Nutrition, Physical Activity, and the Prevention of Breast Cancer. Washington DC, USA: AICR. (available at http://www.dietandcancerreport.org)

World Cancer Research Fund/American Institute for Cancer Research 2011 Continuous Update Project Report. Food, Nutrition, Physical Activity, and the Prevention of Colorectal Cancer. Washington DC, USA: AICR. (available at http://www.dietandcancerreport.org)

World Cancer Research Fund/American Institute for Cancer Research 2012 Continuous Update Project Report. Food, Nutrition, Physical Activity, and the Prevention of Pancreatic Cancer. Washington DC, USA: AICR. (available at http://www.dietandcancerreport.org)

World Cancer Research Fund/American Institute for Cancer Research 2013 Continuous Update Project Report. Food, Nutrition, Physical Activity, and the Prevention of Endometrial Cancer. Washington DC, USA: AICR. (available at http://www.dietandcancerreport.org)

World Cancer Research Fund/American Institute for Cancer Research $2014 a$ Continuous Update Project Report. Food, Nutrition, Physical Activity, and the Prevention of Ovarian Cancer. Washington DC, USA: AICR. (available at http://www.dietandcancerreport.org)

World Cancer Research Fund International 2014b Continuous Update Project Report: Diet, Nutrition, Physical Activity, and Prostate Cancer. Washington DC, USA: AICR. (available at www.wcrf.org/sites/default/ files/Prostate-Cancer-2014-Report.pdf)

World Cancer Research Fund International 2015 Continuous Update Project Report. Food, Nutrition, Physical Activity, and the Prevention of Liver Cancer. Washington DC, USA: AICR. (available at http://www. dietandcancerreport.org)

Received in final form 3 March 2015

Accepted 1 April 2015

Made available online as an Accepted Preprint

13 April 2015
(C) 2015 Society for Endocrinology Printed in Great Britain 